\title{
Rancang Bangun Sistem Informasi Pengelolaan Sales Order dan Bill of Material Interior dan Exterior Bangunan Menggunakan Model Waterfall
}

\author{
Kusmayanti Solecha ${ }^{1}$, Eka Rini Yulia ${ }^{2}$ \\ Universitas Bina Sarana Informatika, STMIK Nusa Mandiri \\ Kusmayanti.ksc@bsi.ac.id, eka.erl@nusamandiri.ac.id
}

\begin{abstract}
Abstrak
CV. Ginnozu Cipta Komunikasi merupakan perusahaan yang bergerak di bidang bidang interior dan exterior untuk bangunan produk yang dihasilkan seperti pintu, meja, pagar dan lain-lain. Proses sales order dan Bill Of Material yang dilakukan oleh - CV. Ginnozu Cipta Komunikasi saat ini membutuhkan waktu yang lama dan terkendala pada pengarsipan model furniture sehingga kurang efektif dan efisien. Tujuan penelitian ini adalah membuat Sistem Informasi Pengelolaan Sales Order dan Bill of Material Interior dan Exterior Bangunan. Dalam metode penelitian ini, metode yang digunakan yaitu metode waterfall sebagai pola pengembangan sistem. Sedangkan pembuatan perangkat lunak dalam penelitian ini, penulis menggunakan perangkat lunak Java NetBeans IDE 8.1 dan untuk basis datanya menggunakan MySQL. Hasil penelitian ini adalah Sistem Informasi Pengelolaan Sales Order dan Bill of Material Interior dan Exterior Bangunan yang dapat digunakan untuk membantu sales dan customer dalam mengakses informasi mengenai model furniture serta dalam melakukan Sales Order. Kata kunci: sistem informasi, sales order, waterfall
\end{abstract}

\begin{abstract}
CV. Ginnozu Cipta Communication is a company engaged in the field of interior and exterior for the building of products produced such as doors, tables, fences and others. Process Of Sales order and Bill of Material carried out by-CV. Ginnozu Cipta Communication currently takes a long time and is constrained to the archiving of furniture models so it is less effective and efficient. The purpose of this research is to make the information System Management Sales Order and Bill of Material Interior and Exterior building. In this method of research, the method used is waterfall method as a pattern of system development. While the creation of software in this research, authors use the Java NetBeans IDE software 8.1 and for its database using MySQL. The results of this research are information System Management Sales Order and Bill of Material Interior and Exterior building that can be used to assist sales and customer in accessing information about furniture models and in conducting Sales orders.
\end{abstract}

Keywords : Information systems, sales orders, waterfall

\section{PENDAHULUAN}

Salah satu perubahan yang terjadi pada dunia teknologi informasi adalah sebuah sistem informasi di suatu perusahaan (Utama, Lanang, Raditya, \& Satwika, 2019). Kebutuhan akan informasi yang cepat dan akurat sangat dibutuhkan oleh setiap perusahaan (Erawati, 2019). Penggunaan sistem informasi pada sebuah perusahaan dapat mempercepat berbagai proses di suatu perusahaan seperti pembuatan laporan transaksi dan dokuem lainnya (Utama et al., 2019).
CV. Ginnozu Cipta Komunikasi merupakan perusahaan yang kegiatan utamanya mengolah bahan baku menjadi bahan jadi siap jual. CV. Ginnozu Cipta Komunikasi bergerak di bidang interior dan exterior untuk bangunan produk yang dihasilkan seperti pintu, meja, pagar dan lain-lain.

Masalah utama yang terjadi pada CV. Ginnozu Cipta Komunikasi yaitu pada saat proses bisnis seperti sales order (Graha \& Abadi, 2017) dan bill of material (Utama et al., 2019) tidak dapat dibuat tepat waktu. Kendala lain terjadi 
pada pengarsipan model interion dan model exterior. File model tersebar dan susah untuk mendapatkan model tertentu saat dibutuhkan. Sehingga dalam penyajian informasi yang dibutuhkan terasa lama dan merepotkan (Atikah, 2016) ini mengakibatkan keterlambatan dalam proses sales order dan pembuatan bill of material ini berdampak pada customer sehingga bisa berdampak kepada loyalitas customer yang nantinya akan berkurang.

Dalam menyelesaikan permasalahan diatas yaitu dengan menggunakan sistem informasi. pentingnya data yang akurat tentang pengelolaan sales order dan bill of material, maka penulis melakukan penelitian, analisa dan perancangan sistem informasi pengelolaan sales order dan bill of material dengan tujuan membantu CV Ginnozu Cipta Komunikasi dalam perancangan sistem informasi pengelolaan sales order dan bill of material interior dan exterior bangunan dengan menggunakan komputer sebagai alat bantu pengolahan data. Diharapkan sistem informasi pengelolaan sales order dan bill of material interior dan exterior bangunan dapat memberi informasi yang cepat untuk kelancaran proses sales order dan bill of material.

\section{METODE}

Sistem Informasi Pengelolaan persediaan bahan baku dengan menggunakan model waterfall, model waterfall adalah salah satu model SDLC yang sering digunakan atau sering disebut juga dengan model konvensional atau classic life cycle (Susanto, R., Andriana, A. D., Susanto, R., \& Andriana, 2016).

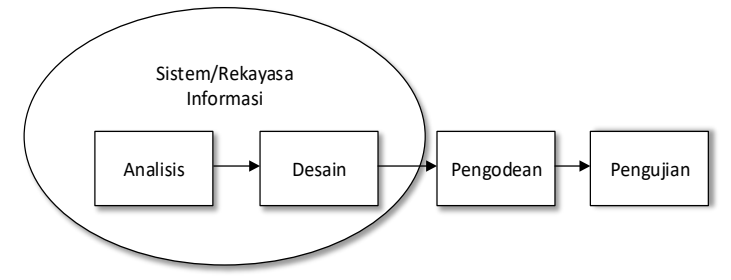

Sumber : (Sukamto \& Shalahuddin, 2016)

Gambar 1 Model Waterfall

a. Analisa kebutuhan software. Suatu proses kebutuhan pengumpulan software untuk mengerti sifat-sifat program yang dibentuk software engineering. b. Desain software sesungguhnya adalah proses Multi step yang memfokuskan pada 3 atribut program yang berbeda yaitu struktur data, arsitektur software dan rincian prosedur.

c. Code Generation mendesain apa saja yang diperlukan dalam pembuatan aplikasi ini menggunakan Java NetBeans IDE 8.1 dan database MYSQL.

d. Testing Setelah obyek program dihasilkan, pengetesan program dimulai.

\section{HASIL}

Penelitian ini menghasilkan sebuah sistem berbasis komputer yang dibangun berdasarkan kebutuhan yang akan digunakan pada Sistem Informasi Pengelolaan Sales Order dan Bill of Material Interior dan Exterior Bangunan.

\section{Analisa Kebutuhan Software}

Berdasarkan hasil analisa, sistem yang akan dikembangkan, diantaranya: Sales dapat masuk kedalam sistem untuk mengelola transaksi sales order, mengelola data customer dan mengakses laporan sales order. Desainer dapat masuk kedalam sistem untuk mengelola data master berupa data furniture, data model, mengakses transaksi bill of material setelah Sales membuat order, melihat laporan sales order. Bagian gudang dapat masuk kedalam sistem untuk mengelola material dan mengakses laporan material. Pimpinan dapat masuk kedalam sistem untuk mengesahkan RAB dari hasil pembuatan bill of material dan melihat laporan sales order dan laporan stok material.

Spesifikasi kebutuhan perangkat lunak pada penelitian ini antara lain :

a. Analisa kebutuhan sales akan sistem:
a. 1. Sales login
a. 2. Sales mengelola transaksi sales order.
a. 3. Sales mengakses laporan sales order.

b. Analisa kebutuhan desainer akan sistem:

b. 1. Desainer login

b. 2. Desainer mengelola data furniture.

b. 3. Desainer mengelola data model.

b. 4. Desainer mengelola transaksi Bill of Material.

b. 5. Sales mengakses laporan sales order

c. Analisa kebutuhan Bagian Gudang akan sistem

c.1. Bagian Gudang login 
c.2. Bagian Gudang mengelola data material.

c.3. Bagian Gudang mengakses laporan material.

d. Analisa kebutuhan pimpinan akan sistem

d.1. Pimpinan login

d.2. Pimpinan mengakres data transaksi sales order untuk mengesahkan RAB.

d.3. Pimpinan mengakses laporan sales order.

\section{Desain Software}

a. Use Case Diagram

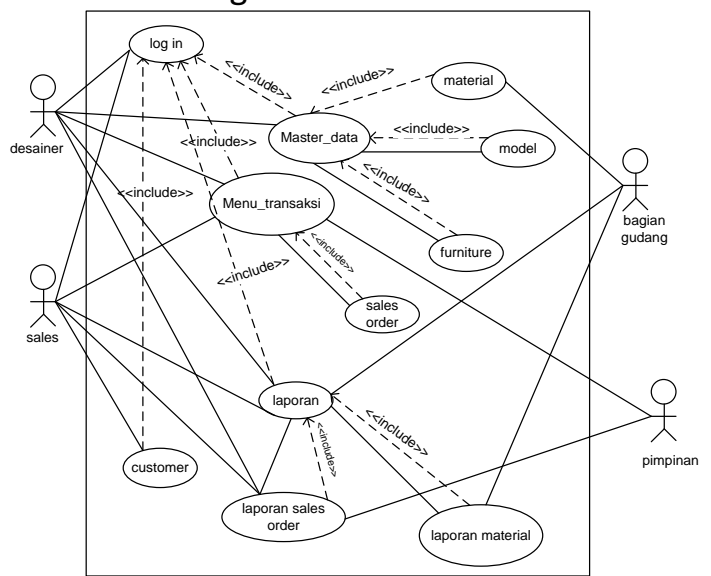

Gambar 2 Use Case Diagram Sistem Informasi

Pengelolaan Sales Order dan Bill of Material Interior dan Exterior Bangunan

Gambar 2 diatas merupakan use case diagram dimana setiap user dapat masuk kedalam sistem informasi pengelolaan sales order dan bill of material interior dan exterior bangunan dengan hak akses masing-masing user.

Tabel 1 Deskripsi Use Case mengelola Menu Master

\section{Use Case Narative Mengelola Menu Master}

Tujuan

User dapat melakukan pengolahan data master seperti tambah, simpan, hapus, cari, batal dari menu master

Deskripasi System ini memungkinkan actor untuk mengelola data master seperti tambah, simpan, hapus, cari, batal dari menu master.
Tabel 2 Deskripsi Use Case mengelola Menu Transaksi

Use Case Narative Mengelola Menu Transaksi

Tujuan

User dapat melakukan pengolahan data transaksi order, dimana setiap actor memilihi hak akses masingmasing

Deskripasi Sistem ini memungkinkan actor untuk mengelola data seperti sales bisa membuat order, setelah order dibuat disainer bisa langsung membuat rancangan desain interior dan exterior bangunan berdasarkan model dan material yang telah tersedia, pimpinan akan menyetujui $R A B$ yang telah dibuat berdasarkan rancangan yang telah dibuat oleh desainer.

Tabel 3 Deskripsi Use Case mengelola Menu Laporan

\begin{tabular}{ll}
\multicolumn{2}{c}{ Use Case \begin{tabular}{c}
\multicolumn{1}{c}{ Larative Mengelola Menu } \\
Laporan
\end{tabular}} \\
Tujuan & $\begin{array}{l}\text { User dapat melakukan } \\
\text { pengolahan menu laporan, } \\
\text { dimana setiap aktor memilihi } \\
\text { hak akses masing-masing. }\end{array}$ \\
Deskripasi & $\begin{array}{l}\text { Sistem ini memungkinkan aktor } \\
\text { bisa mengakses laporan sales } \\
\text { order dan laporan material }\end{array}$
\end{tabular}

b. Activity Diagram

b. 1. Activity Diagram Menu Utama

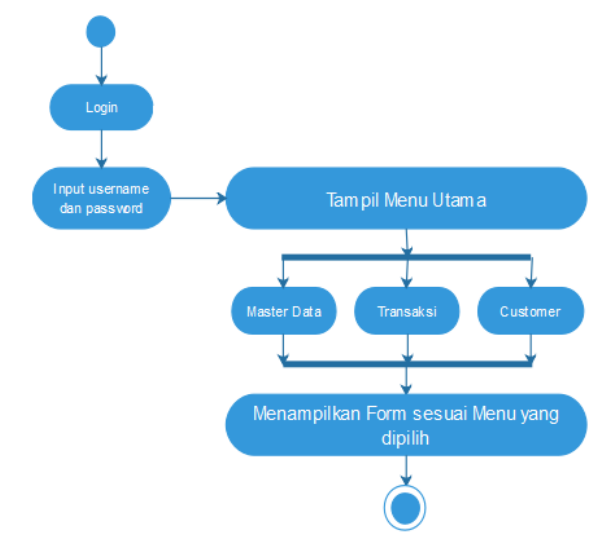

Gambar 3 Activity Diagram Menu Utama 
b. 2. Activity Diagram Menu Master Data

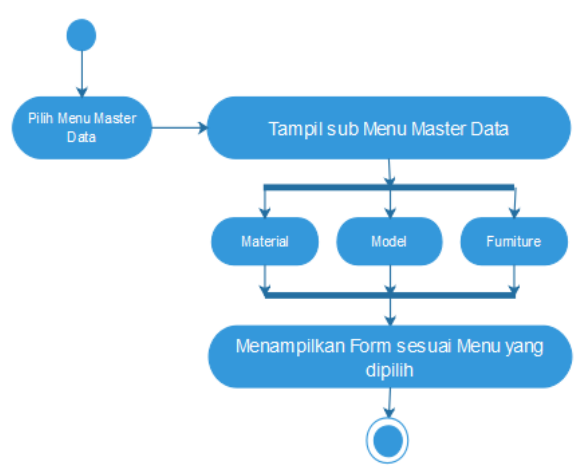

Gambar 4 Activity Diagram Menu Master Data

b. 3. Activity Diagram Menu Transaksi

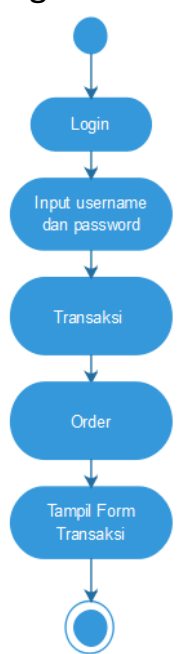

Gambar 5 Activity Diagram Menu Transaksi

b. 4. Activity Diagram Menu Customer

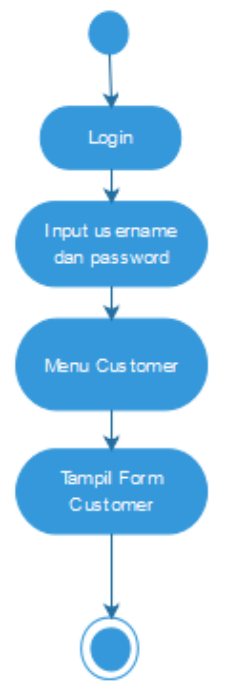

Gambar 6 Activity Diagram Menu Customer b. 5. Activity Diagram Menu Laporan

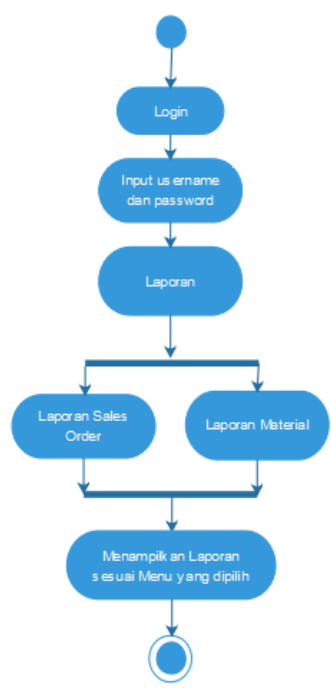

Gambar 7 Activity Diagram Menu Laporan c. Logical Record Structure (LRS)

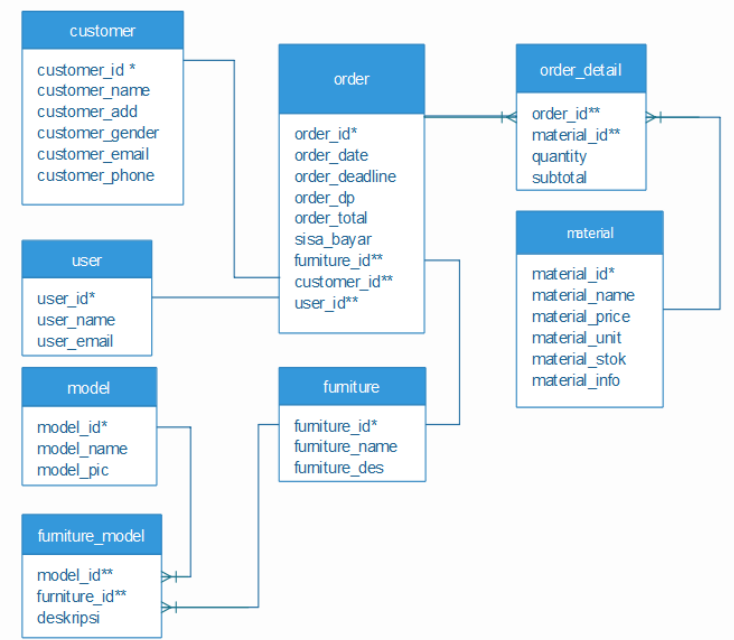

Gambar 8 Logical Record Structure (LRS) Sistem Informasi Pengelolaan Sales Order dan Bill of Material Interior dan Exterior Bangunan

d. Entity Relation Diagram (ERD)

Berikut Entuty Relationship Diagram (ERD) pada Sistem Informasi Pengelolaan Sales Order dan Bill of Material Interior dan Exterior Bangunan. 


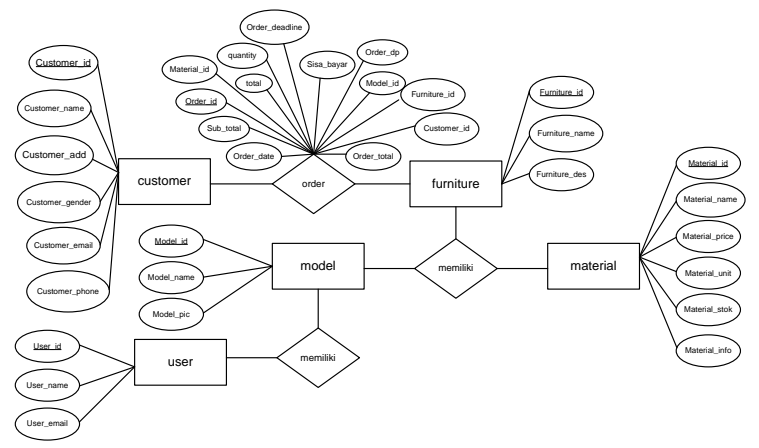

Gambar 9 Entity Relation Diagram (ERD) Sistem Informasi Pengelolaan Sales Order dan Bill of

Material Interior dan Exterior Bangunan

Pada Gambar 9 adalah Entity Relation Diagram (ERD), yang merupakan menjadi dasar dalam perancangan database pada Sistem Informasi Pengelolaan Sales Order dan Bill of Material Interior dan Exterior Bangunan.

\section{e. User Interface}

Setelah menerapkan kode pemrograman dengan bahasa pemrograman utamanya menggunakan bahasa pemrograman Java NetBeans IDE 8.1 dan database MYSQL, berikut ini hasil tampilan halaman Sistem Informasi Pengelolaan Sales Order dan Bill of Material Interior dan Exterior Bangunan.

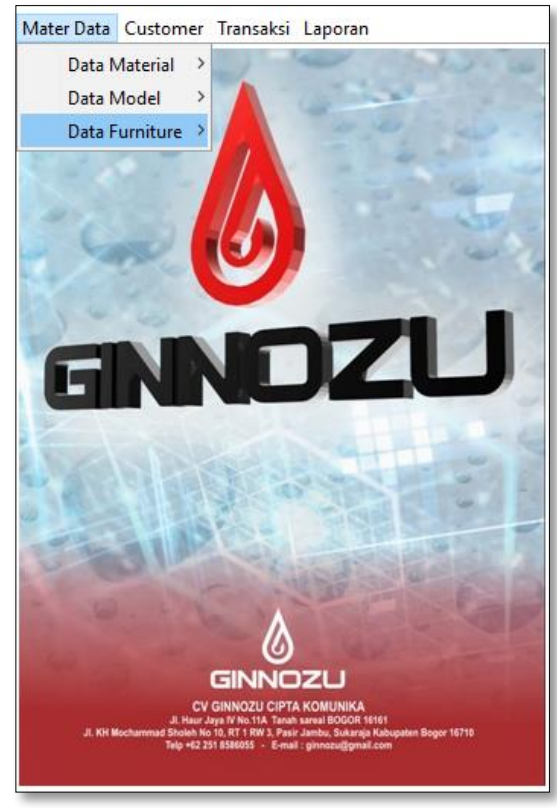

Gambar 10 Menu Utama pada Sistem Informasi Pengelolaan Sales Order dan Bill of Material Interior dan Exterior Bangunan

Merupakan implementasi dari halaman menu utama. Terdapat menu Master, Transaksi,

http://ejournal.urindo.ac.id/index.php/TI
Customer dimana setiap pengguna sudah diatur dengan hak akses masing-masing pengguna.

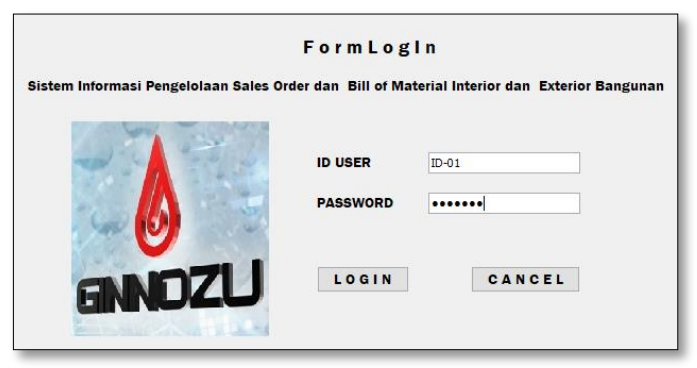

Gambar 11 Tampilan Form Login pada Sistem Informasi Pengelolaan Sales Order dan Bill of Material Interior dan Exterior Bangunan

Merupakan implementasi dari form login yang bertujuan untuk memberikan keamanan data dan hanya user yang dapat masuk ke dalam Sistem Informasi Pengelolaan Sales Order dan Bill of Material Interior dan Exterior Bangunan.

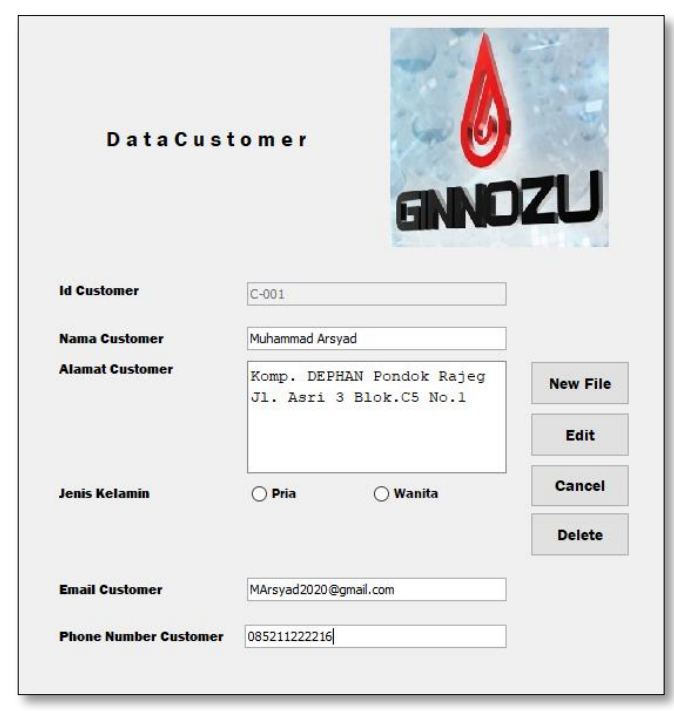

Gambar 12 Tampilan Form Data Customer pada Sistem Informasi Pengelolaan Sales Order dan Bill of Material Interior dan Exterior Bangunan

Merupakan implementasi dari form customer yang bertujuan untuk mendata data pelanggan yang akan melakukan pemesan. 


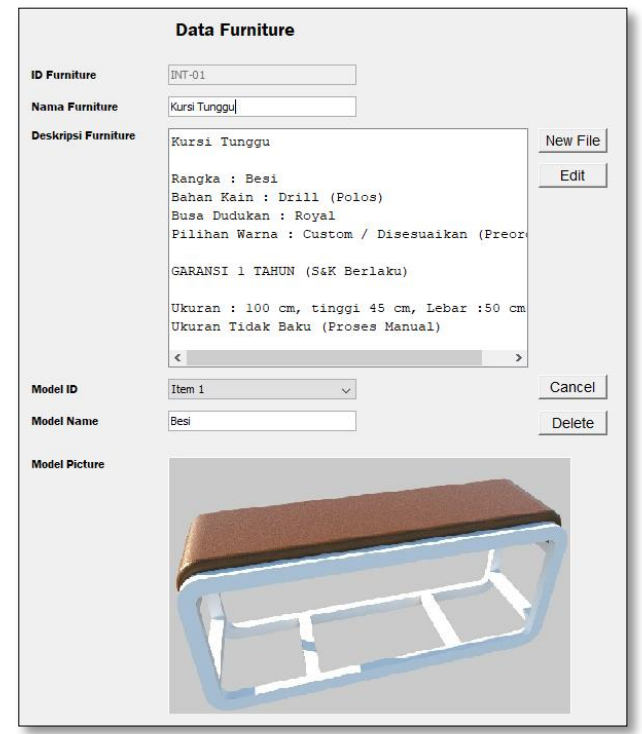

Gambar 13 Tampilan form data furniture pada Sistem Informasi Pengelolaan Sales Order dan Bill of Material Interior dan Exterior Bangunan

Merupakan implementasi dari form data furniture yang bertujuan untuk data furniture yang nantinya akan mempermudah customer dalam memilih model furniture saat proses pemesanan.

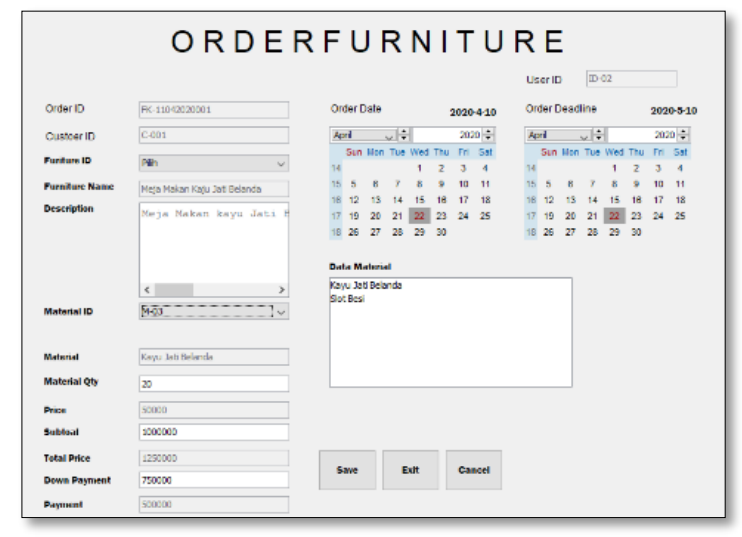

Gambar 14 Tampilan Form Transaksi Sales Order dan Bill of Material

Merupakan implementasi dari form transaksi Sales Order dan Bill of Material yang diperlukan dalam proses pemesanan dan berhitungan bahan baku.

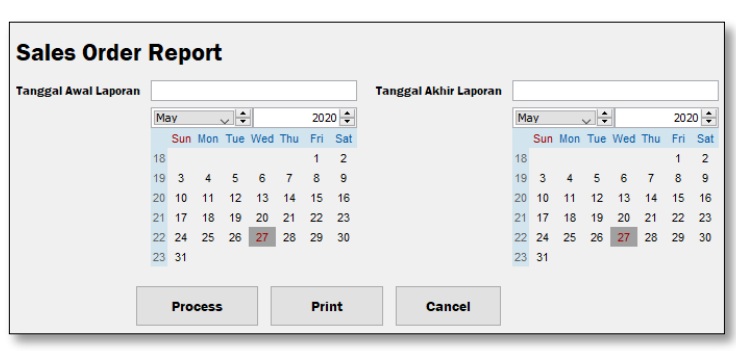

Gambar 15 Tampilan Sales Order Report pada Sistem Informasi Pengelolaan Sales Order dan Bill of Material Interior dan Exterior Bangunan

\section{Code Generation}

Pada pembuatan Sistem Informasi Pengelolaan Sales Order dan Bill of Material Interior dan Exterior Bangunan, menggunakan bahasa pemrograman Java NetBeans IDE 8.1.

\section{Testing}

Pengujian system dilakukan dengan menggunakan metode black box testing.

Tabel 4 Hasil pengujian black box testing pada

\begin{tabular}{|c|c|c|c|c|c|}
\hline No & $\begin{array}{c}\text { Skenari } \\
0\end{array}$ & Test Case & $\begin{array}{c}\text { Hasil } \\
\text { yang } \\
\text { diharapk } \\
\text { an }\end{array}$ & $\begin{array}{c}\text { Hasil } \\
\text { Penguj } \\
\text { ian }\end{array}$ & $\begin{array}{c}\text { Kesimp } \\
\text { ulan }\end{array}$ \\
\hline 1 & $\begin{array}{l}\text { User ID } \\
\text { dan } \\
\text { passwo } \\
\text { rd } \\
\text { tidak } \\
\text { diisi } \\
\text { kemudi } \\
\text { an di } \\
\text { klik } \\
\text { tombol } \\
\text { login }\end{array}$ & $\begin{array}{l}\text { User ID = } \\
\text { kosong } \\
\text { Password } \\
=\text { kosong }\end{array}$ & $\begin{array}{l}\text { Sistem } \\
\text { akan } \\
\text { menampi } \\
\text { Ikan } \\
\text { pesan } \\
\text { “Masukk } \\
\text { an User } \\
\text { ID" dan } \\
\text { kembali } \\
\text { ke Form } \\
\text { Login }\end{array}$ & $\begin{array}{l}\text { Sesuai } \\
\text { harapa } \\
\text { n }\end{array}$ & Valid \\
\hline 2 & $\begin{array}{l}\text { Masuk } \\
\text { kan } \\
\text { User ID } \\
\text { dan } \\
\text { passwo } \\
\text { rd } \\
\text { tidak } \\
\text { diisi } \\
\text { kemudi } \\
\text { an } \\
\text { tekan } \\
\text { login }\end{array}$ & $\begin{array}{l}\text { User ID = } \\
\text { ID-01 } \\
\text { Password } \\
=\text { kosong }\end{array}$ & $\begin{array}{l}\text { Sistem } \\
\text { akan } \\
\text { menampi } \\
\text { lkan } \\
\text { pesan } \\
\text { "Masukk } \\
\text { an } \\
\text { Password } \\
\text { " }\end{array}$ & $\begin{array}{l}\text { Sesuai } \\
\text { harapa } \\
n\end{array}$ & Valid \\
\hline 3 & $\begin{array}{l}\text { Masuk } \\
\text { kan } \\
\text { User ID } \\
\text { dan } \\
\text { passwo } \\
\text { rd } \\
\text { tidak } \\
\text { valid }\end{array}$ & $\begin{array}{l}\text { User ID = } \\
\text { ID-01 } \\
\text { Password } \\
= \\
* * * * * * *\end{array}$ & $\begin{array}{l}\text { Sistem } \\
\text { akan } \\
\text { menampi } \\
\text { Ikan } \\
\text { pesan } \\
\text { "Passwor } \\
\text { d dan } \\
\text { User ID } \\
\text { tidak } \\
\text { Valid" } \\
\text { dan }\end{array}$ & $\begin{array}{l}\text { Sesuai } \\
\text { harapa } \\
\text { n }\end{array}$ & Valid \\
\hline
\end{tabular}




\begin{tabular}{|c|c|c|c|c|c|}
\hline No & $\begin{array}{c}\text { Skenari } \\
0\end{array}$ & Test Case & $\begin{array}{c}\text { Hasil } \\
\text { yang } \\
\text { diharapk } \\
\text { an }\end{array}$ & $\begin{array}{l}\text { Hasil } \\
\text { Penguj } \\
\text { ian }\end{array}$ & $\begin{array}{c}\text { Kesimp } \\
\text { ulan }\end{array}$ \\
\hline 4 & $\begin{array}{l}\text { Masuk } \\
\text { kan } \\
\text { User ID } \\
\text { dan } \\
\text { passwo } \\
\text { rd yang } \\
\text { valid }\end{array}$ & $\begin{array}{l}\text { User ID = } \\
\text { ID-01 } \\
\text { Password } \\
= \\
* * * * * * *\end{array}$ & $\begin{array}{l}\text { textbox } \\
\text { User ID } \\
\text { dan } \\
\text { Password } \\
\text { kembali } \\
\text { kosong } \\
\text { Sistem } \\
\text { akan } \\
\text { menampi } \\
\text { Ikan } \\
\text { pesan } \\
\text { "Selamat } \\
\text { datang } \\
\text { Sistem } \\
\text { Informasi } \\
\text { Pengelola } \\
\text { an Sales } \\
\text { Order } \\
\text { dan Bill } \\
\text { of } \\
\text { Material } \\
\text { Interior } \\
\text { dan } \\
\text { Exterior } \\
\text { Banguna } \\
\text { n" dan } \\
\text { masuk ke } \\
\text { Menu } \\
\text { Utama }\end{array}$ & $\begin{array}{l}\text { Sesuai } \\
\text { harapa } \\
n\end{array}$ & Valid \\
\hline
\end{tabular}

\section{KESIMPULAN}

Berdasarkan pembahasan mengenai perancangan Sistem Informasi Pengelolaan Sales Order dan Bill of Material Interior dan Exterior Bangunan yang sebelumnya menggunakan sistem konvensional telah diambil alih oleh program, yang saling terintregrasi. Dengan Sistem Informasi Pengelolaan Sales Order dan Bill of Material Interior dan Exterior Bangunan yang telah terkomputerisasi, proses penyimpanan data dalam jumlah besar sudah dapat teratasi. sistem informasi ini mampu memberikan informasi tentang data Sales Order dan Bill of Material akan memudahkan dalam perhitungan rencana anggaran belanja sehingga dapat memudahkan menentukan harga jual ke customer.

\section{DAFTAR PUSTAKA}

1. Atikah. (2016). ANALISA DAN PERANCANGAN SISTEM INFORMASI PENGADAAN BAHAN BAKU PADA PT. XYZ. Jurnal String, 1(2), 109119.

2. Erawati, W. (2019). Perancangan Sistem Informasi Penjualan Dengan Pendekatan Metode Waterfall, 3(1), 1-8. https://doi.org/10.30865/mib.v3i1.987

3. Graha, C. V, \& Abadi, A. (2017). SISTEM INFORMASI PEMESANAN DESAIN INTERIOR DAN EXTERIOR RUMAH BERBASIS WEB STUDI KASUS DI, 80-83.

4. Lasen, S. R. (2013). Analisis Penentuan Harga Pokok Produksi Pada PT. DIMEMBE NYIUR AGRIPRO. Jurnal EMBA, 1(3), 585-592.

5. Sukamto, R. A., \& Shalahuddin, M. (2016). Rekayasa Perangkat Lunak. Bandung: Informatika Bandung.

6. Susanto, R., Andriana, A. D., Susanto, R., \& Andriana, A. D. (2016). Perbandingan Model Waterfall Dan Prototyping. Majalah IImiah UNIKOM, 41-46.

7. Utama, D. W., Lanang, I. G., Raditya, A., \& Satwika, I. P. (2019). Rancang Bangun Sistem Informasi Pemesanan Custom Furniture Berbasis Website, 3, 53-67. 